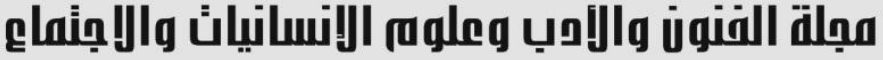

Journal of Arts, Literature, Humanities and Social Sciences

\section{التفسير بين مدرستي مكة والعراق}

د. إبراهيم محمد توفيق زيود كلية الثريعة - جامعة النجاح الوطنية ـ فلسطين الايميل: z.zyoud2015@gmail.com

المدض

يتحدث هذا البحث عن مدرستي التفسير المكية والعر اقية، واللتان يعتبران أبرز مدر اس التفسير و أهمها، فقد كان أصحاب هاتين المدرستين من علماء الصحابة في التفسير ، وأسس كل منهم مدرسته التي اتسمت بطابعها الخاص بها، ويتحدث الباحث عن كل مدرسة من حيث النشأة والتأسبس وأبرز أتباعها، ومكان نشأتها، بالإضافة إلى أبرز خصائص كل من هذه المدرستين، وقد قسم الباحث بحثه إلى بابين، يتتاول في الباب الأول: مدارس التفسير و نشأتها و أبرز أتباعها، وفي الباب الثاني تحدث عن سبب بزوغ ابن عباس وابن مسعود رضي الله عنه، في التفسير ، ثم تحدث أخيراً عن خصائص كل مدرسة من المدرستين. وختم البحث بأبرز النتائج، وأهم المصادر و المراجع التي اعتمد عليها.

الكلمات المفتاحية: المدرسة المكية، المدرسة العر اقية، مدارس التفسير ، ابن عباس، ابن مسعود. 


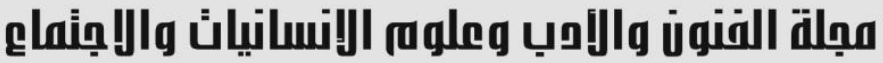

Journal of Arts, Literature, Humanities and Social Sciences

\section{Interpretation Approaches of Maccan and Iraqi School}

\author{
Dr. Ibrahim Mohammad Zyoud \\ College of Sharea' - An-Najah National University - Palestine \\ Email: z.zyoud2015@gmail.com
}

\begin{abstract}
This research discusses two of the most famous and important traditional schools (branches) of Quranic interpretation, which are the Meccan and the Iraqi schools. These two schools gain the interest, since they were founded by the companions (Sahabah) of the prophet Mohammed peace be upon him. Each of these two schools has its own characteristics and remarks. The author investigates the origin, foundation, characteristics, remarks and prominent followers of each of these two schools. This research is divided to two main chapters. The first chapter deals with the foundation and the prominent followers of these two schools. In the second chapter, the characteristics and the reasons behind the emergence of Ibn Abbas and Ibn Masoud, may Allah be pleased with them, have been highlighted. Finally, the research was concluded with the results.
\end{abstract}

Keywords: Ibn Masoud, Ibn Abbas, Mecca school, Iraqi School. 


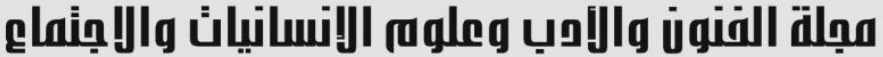

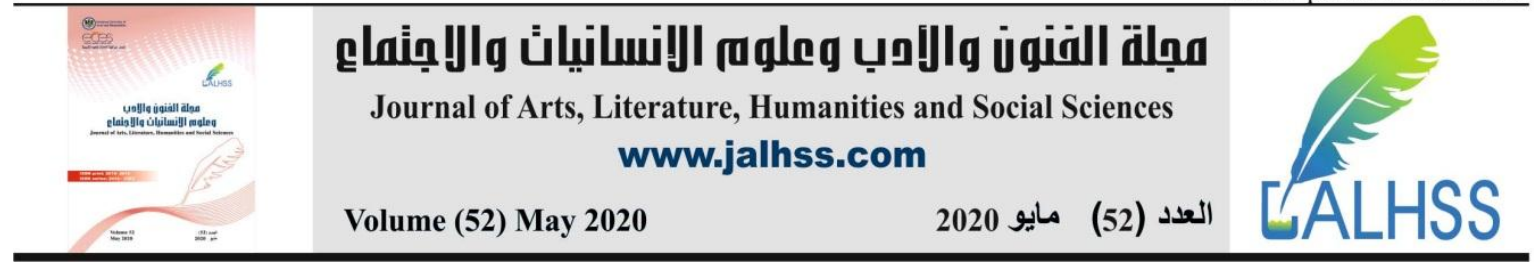

مقدمة

لو أننا رجعنا إلى عهد الصحابة لوجدنا أنهم لم يكونوا في درجة واحدة بالنسبة لفهم معانى القرآن، بل تفاوتت

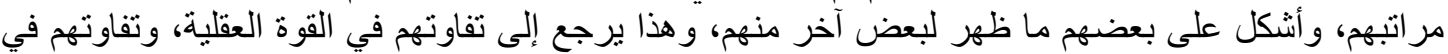

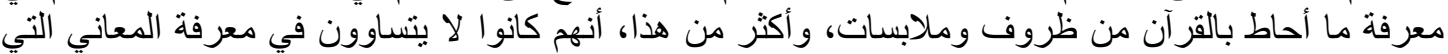

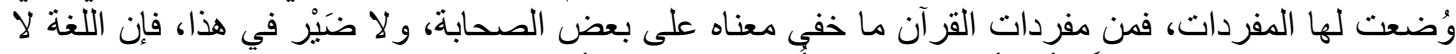

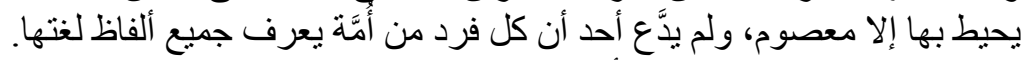

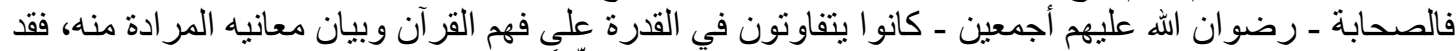

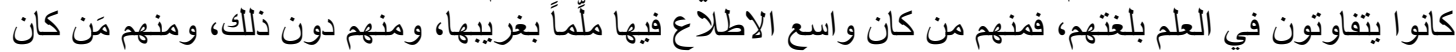

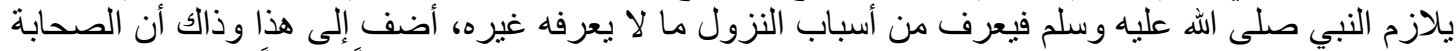

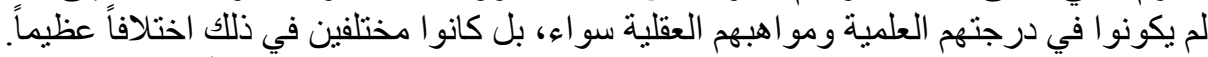

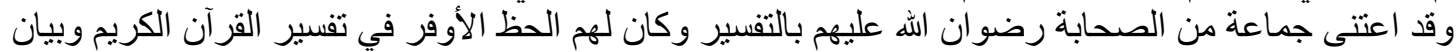

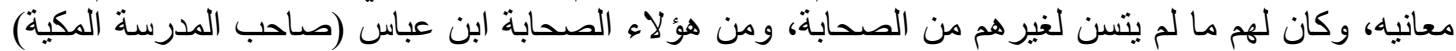

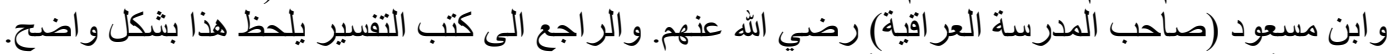

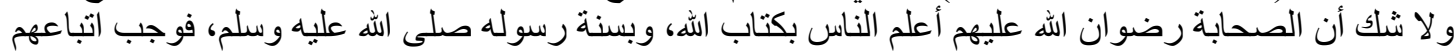

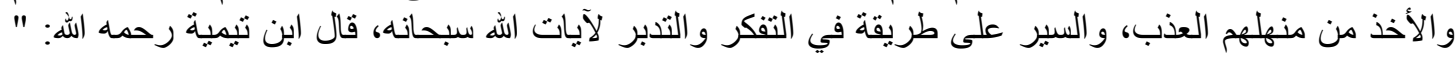

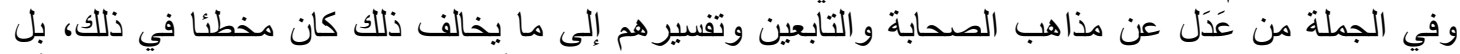

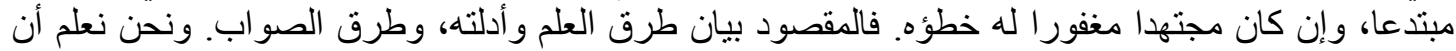

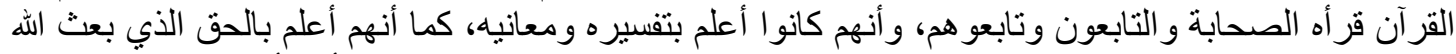

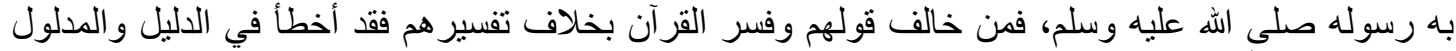

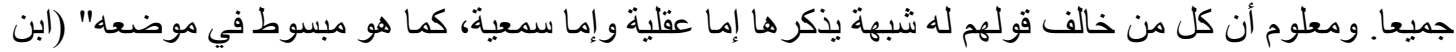

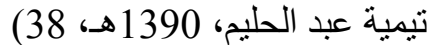
وسنتكلم في هذا البحث عن أهم مدارس التفسير ، و هما مدرسة مكة ومدرسة العراق

$$
\text { الباب الأول }
$$

أولاً: مدارس التفسير:

تعددت مدراس التفسير في عهد الصحابة رضوان الله عليهج، وكان لكل مدرسة خصائصها، ومميزاتها

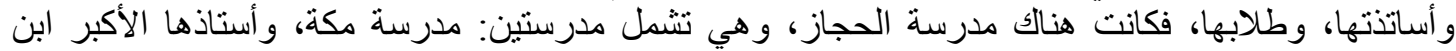

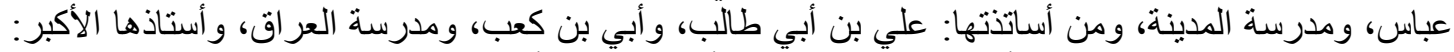

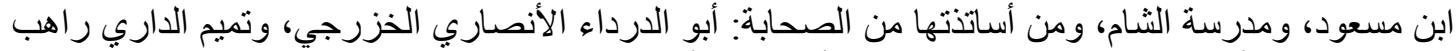

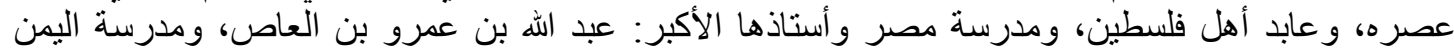

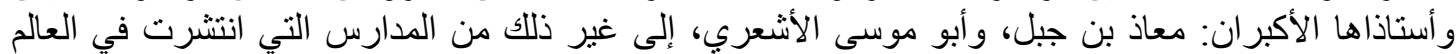

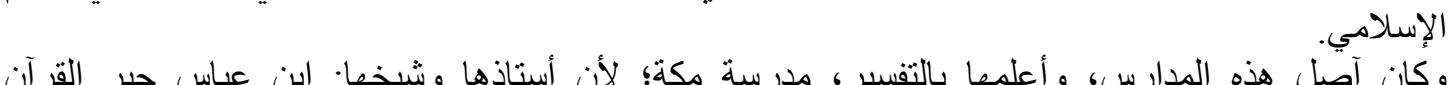

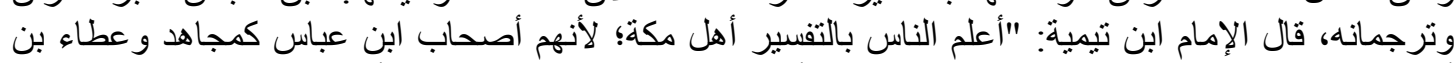

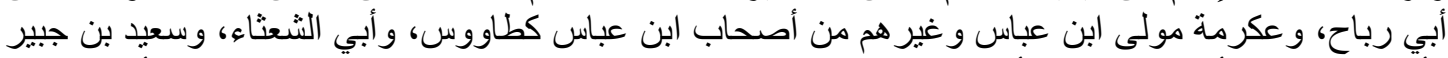

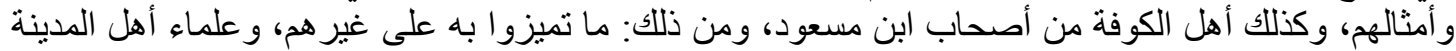

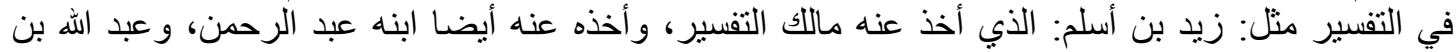
وهب"( المصدر السابق نفسه، 24).

ثانياً: مدرسة أهل مكة

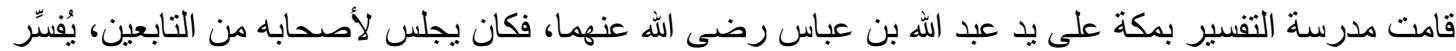

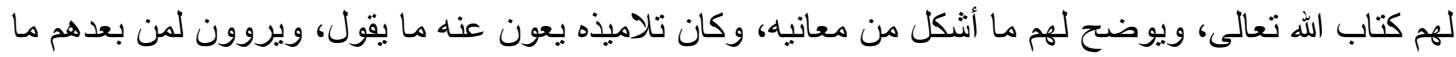




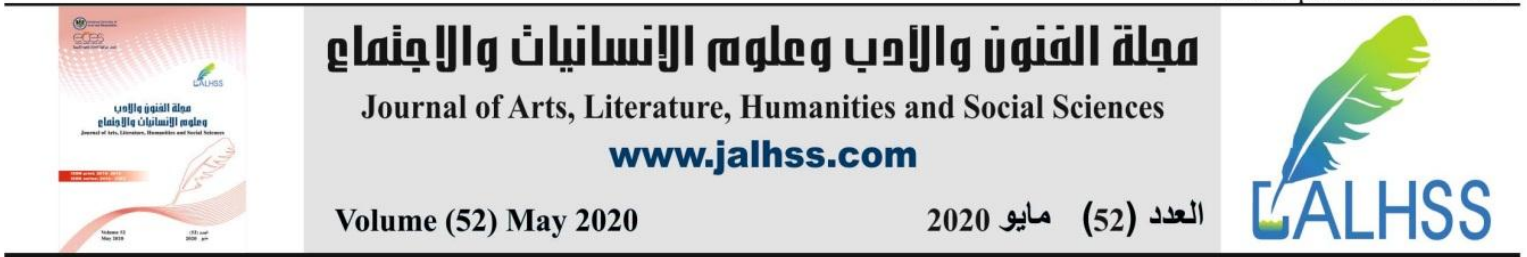

سمعوه منه. فكانت مدرسته التي كان لها سماتها وخصائصها، و أصحاب يقو مون بعلمه، ويقولون بقوله، ونشروا علمه على أوسع ما يكون النشر.

مؤسس هذه المدرسة وأبرز رجالها يعتبر عبد الله بن عباس رضي الله عنهما مؤسس نواة مدرسة أهل مكة ،الملقب بالحبر البحر، وهو هو عبد الله بن

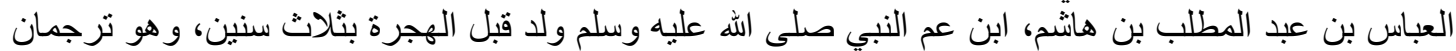

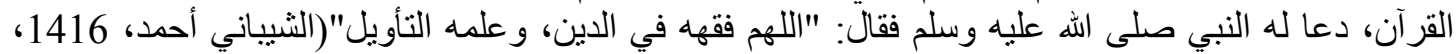

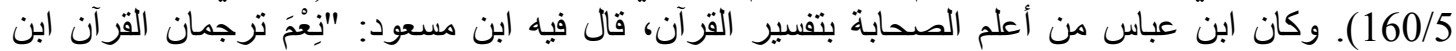

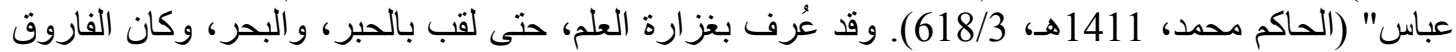

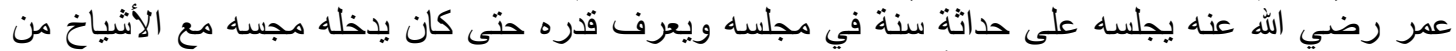

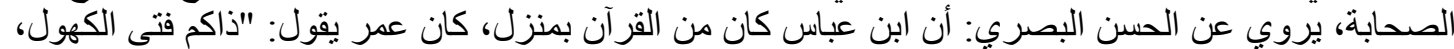

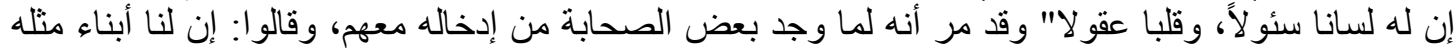

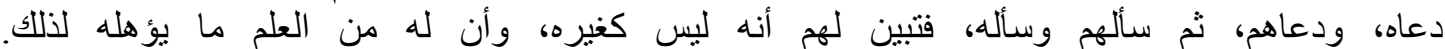

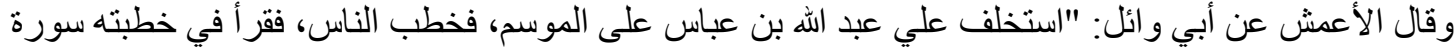

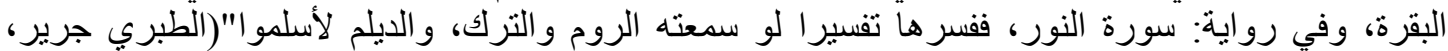
. (81/1

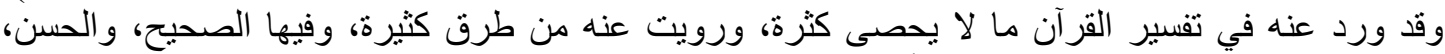

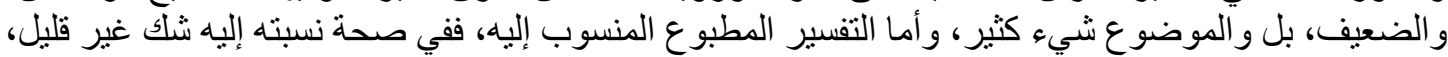

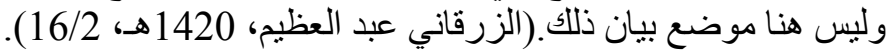

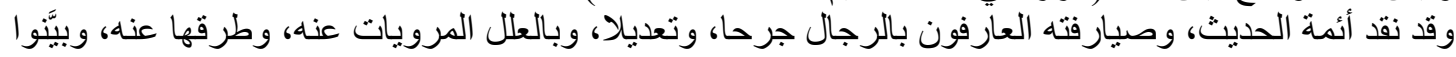

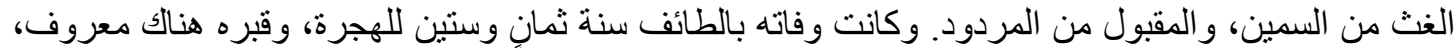

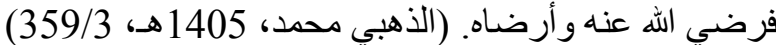
وقد اشتهر من تلاميذ ابن عباس بمكة: 1. سعيد بن جبير بن هشام الأسدي: أبو محمد، حبشي الأصل، أسود اللون، أبيض الخصال، أخذ عن ابن

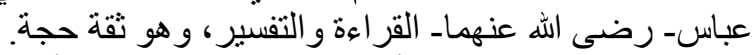

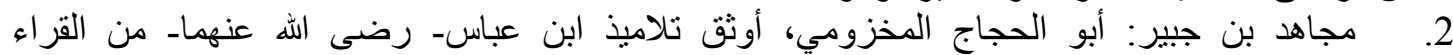

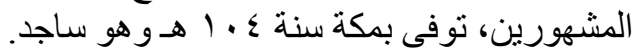

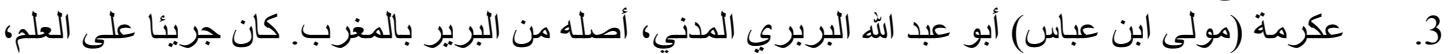

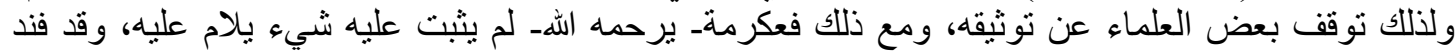

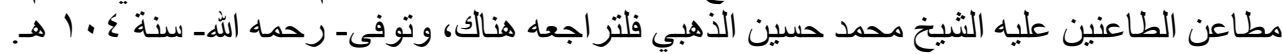

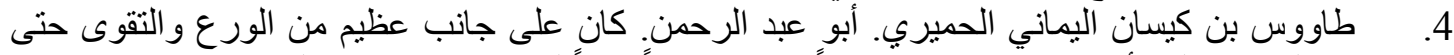

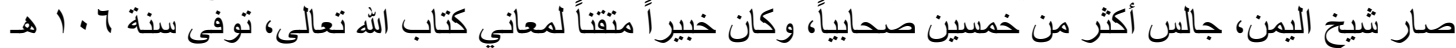
بمكة المكرمة أثناء حجه إليها من اليمن.

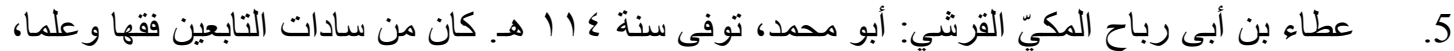

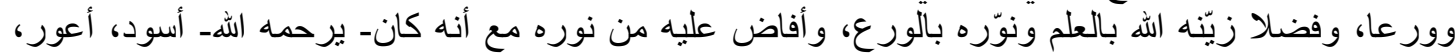

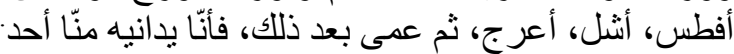

ثالثاً: مدرسة أهل العراق

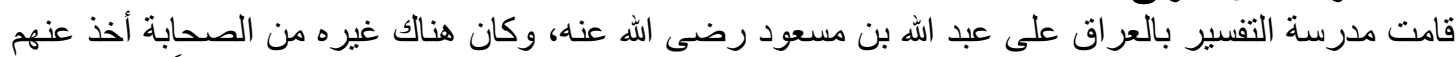

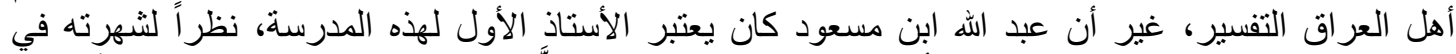

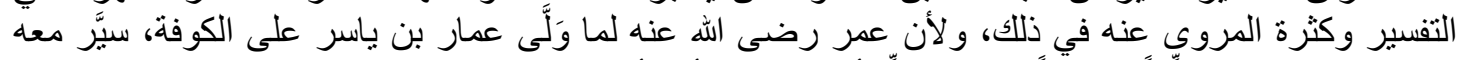

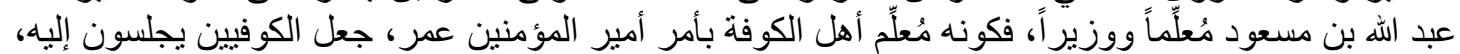

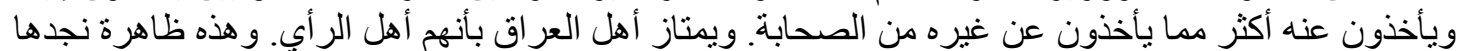

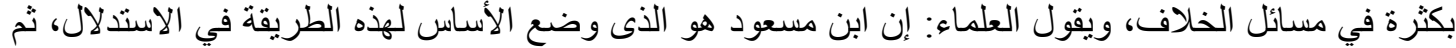




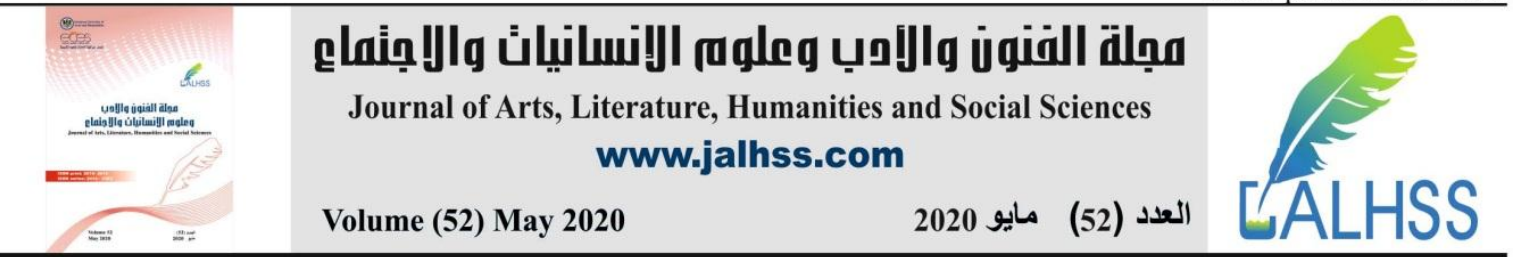

توارثها عنه علماء العراق، ومن الطبيعي أن تؤثر هذه الطريقة في مدرسة التفسير، فيكثر تفسير بالرأي

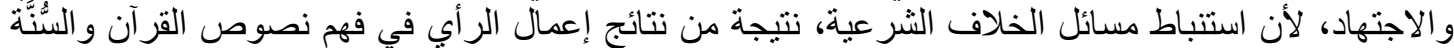

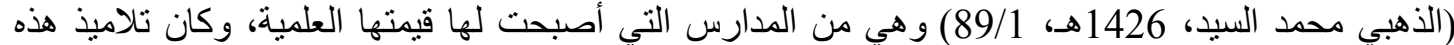
المدرسة منهم من كان ببغداد، ومنهم من كان بالكوفة، ومنهم من كان بالبصرة التهرة

مؤسس هذه المدرسة وأشهر رجالهها

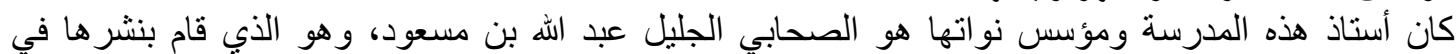

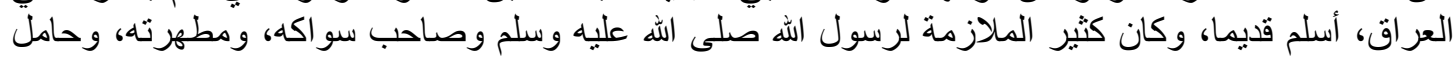

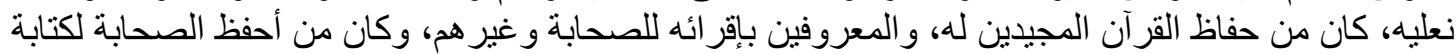

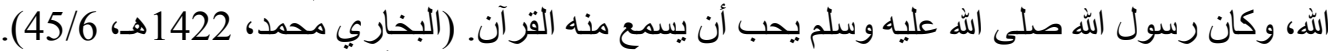

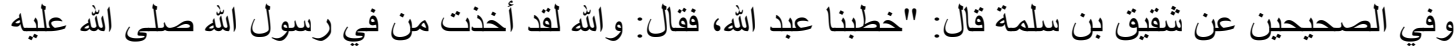
وسلم بضعا وسبعين سورة، و الله لقد علم أصحاب النبي صلى الله عليه وسلم أني من أعلمهر بكتاب الله، وما أنا

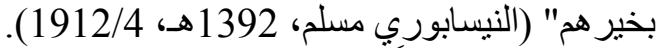
و عند البخاري أيضاً عن مسروق، قال: ذكر عبد الله بن مسعود عند عبد الله بن عمرو -يعني ابن العاص، فقال:

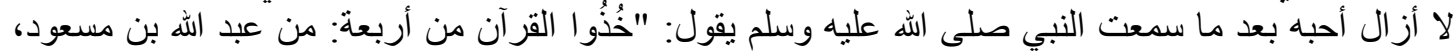

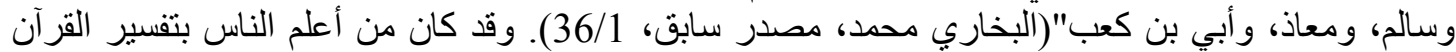

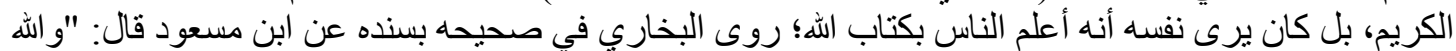

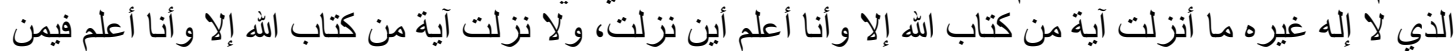

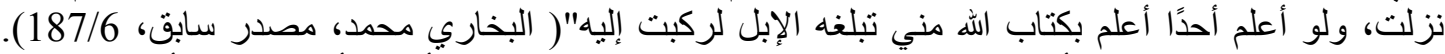

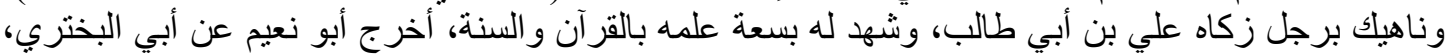

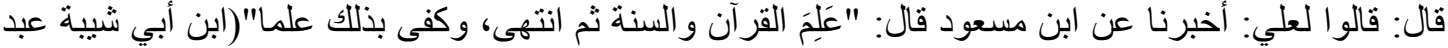

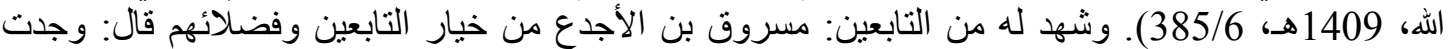

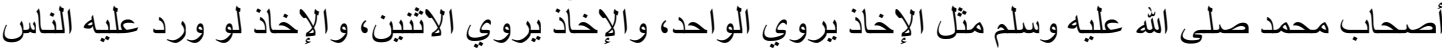

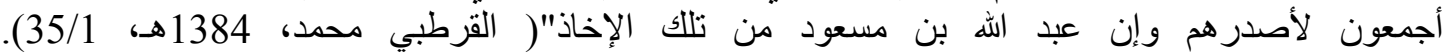

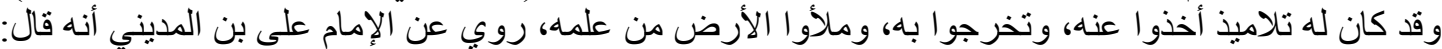

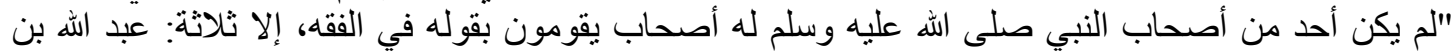

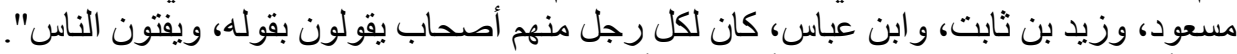

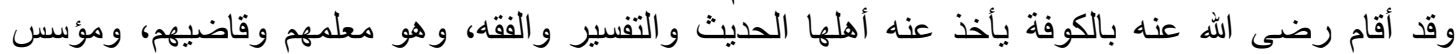

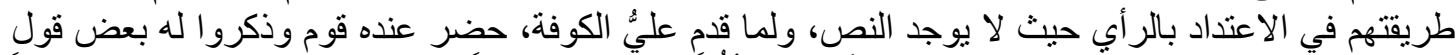

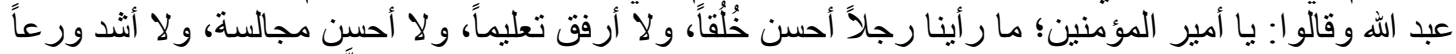

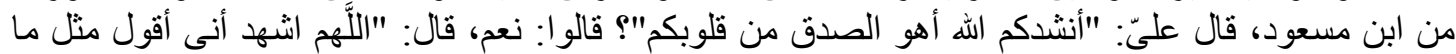

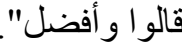

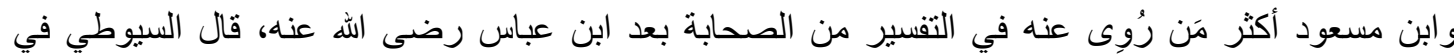

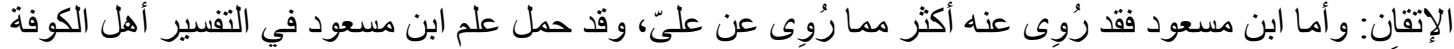

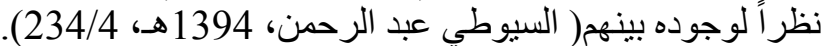
وقد رويت عنه روايات كثيرة في التفسير، وقد عني بها أئمة الحديث ونقدوها، وبينوا الصحيح من الضعيف،

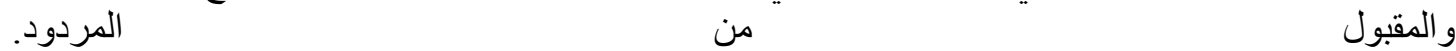
وكانت وفاته سنة اثتنين وثثلاثين، وقيل ثلاث وثثلاثين فرضى الله عنه و أرضاه

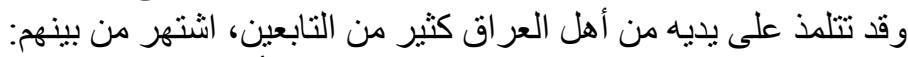

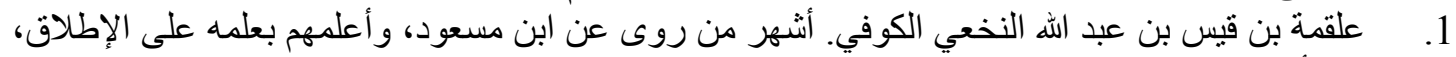

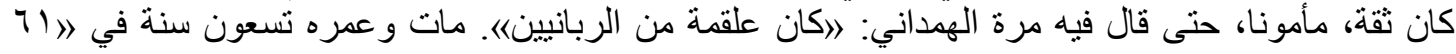




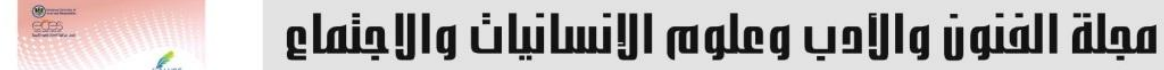 \\ Journal of Arts, Literature, Humanities and Social Sciences www.jalhss.com

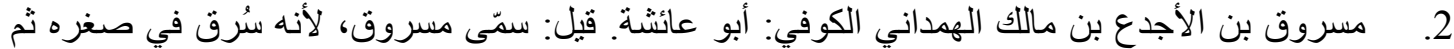

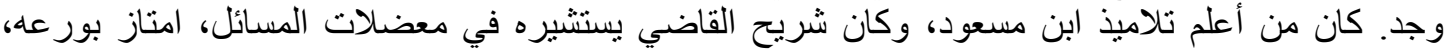

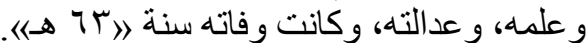

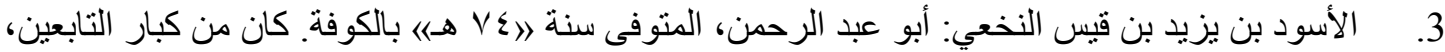

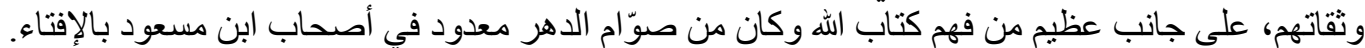

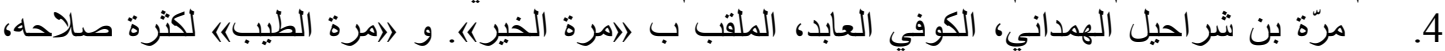

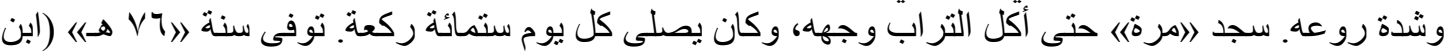

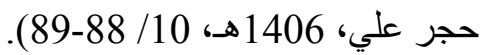

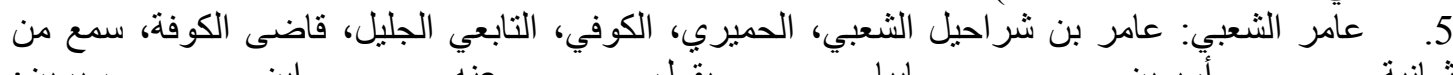

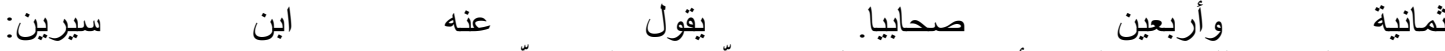
》(قدمت الكوفة وللثعبي حلقة، و أصحاب رسول الله صلّى الله عليه وسلّم يومئذ كثير)، كان فقيها، شاعرا، ثقة، وكان يقال عنه: 》ابن عباس في زمانها《). 6. الحسن البصرى: الحسن بن أبى الحسن يسار البصرى، مولى الأنصار كان غزير العلم بكتاب الله،

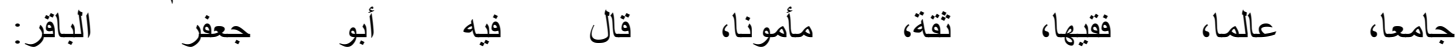
إذللك الذى يشبه كلامه كلام الأنبياء.

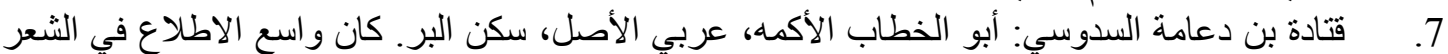

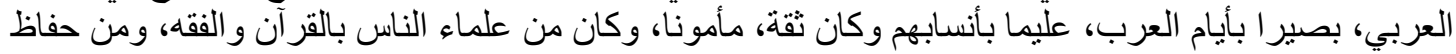

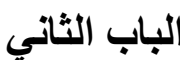

\section{أسباب نبوغ ابن عباس وابن مسعود في التفسير}

ابن عباس: أما ابن عباس رضي الله عنهما فنستطيع أن نُرجع هذه الثهرة العلمية، وهذا النبوغ الواسع الفيّاض، إلى أسباب

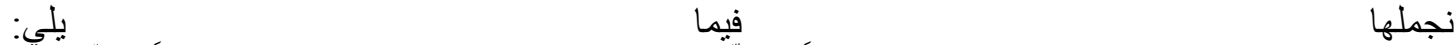

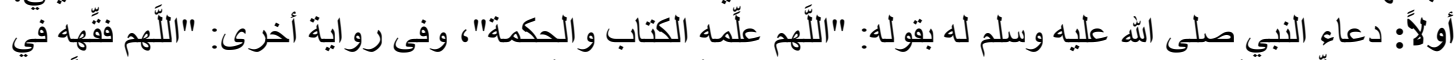

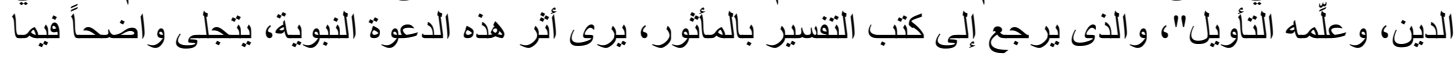

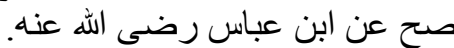

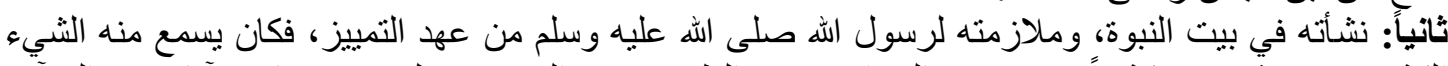

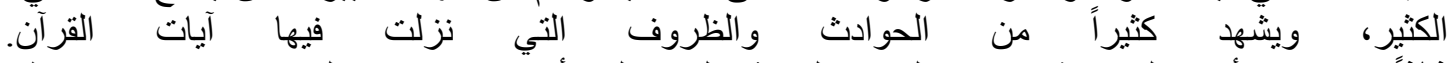

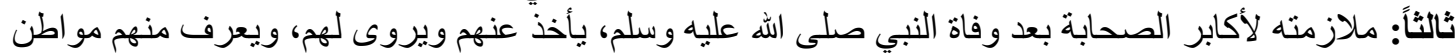

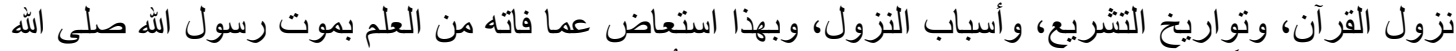

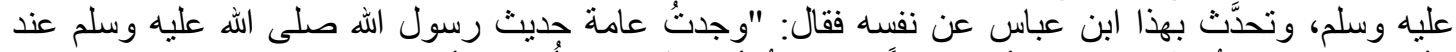

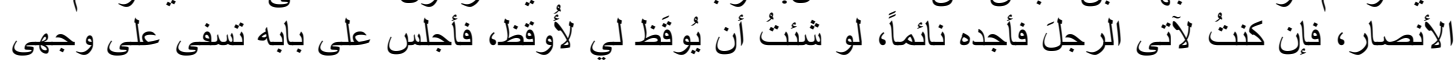

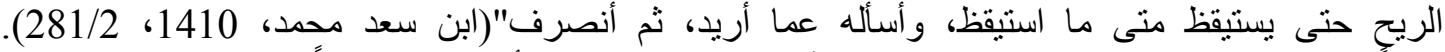

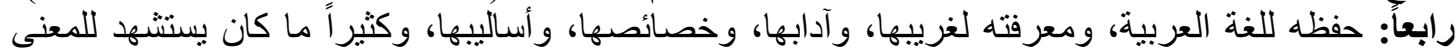

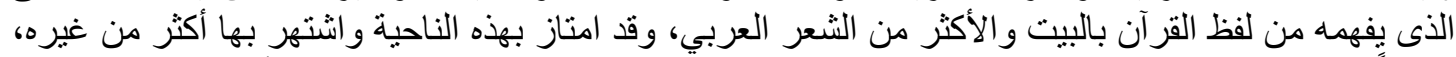

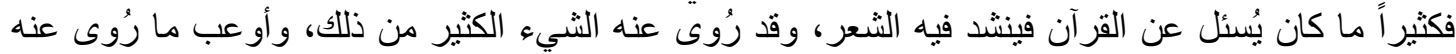

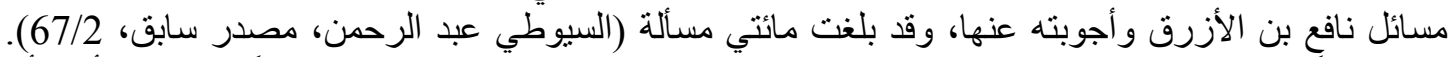

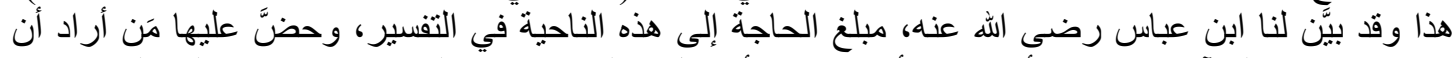

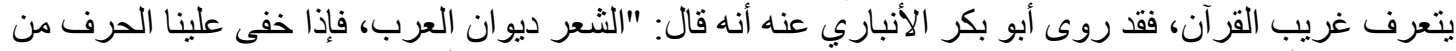

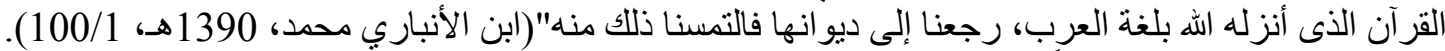

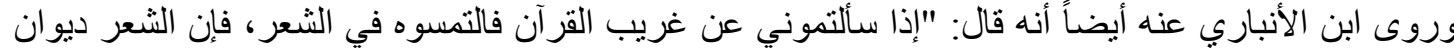
العرب"(المصدر السابق نفسه، 62/1). 


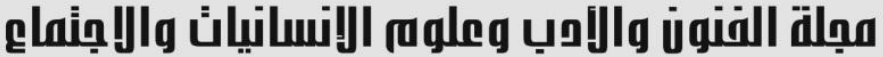 \\ Journal of Arts, Literature, Humanities and Social Sciences}

\section{www.jalhss.com}

فابن عباس رضى الله عنه كان برى رأى عمر في ضرورة الرجوع إلى الثعر الجاهلي، للاستعانة به على فهم

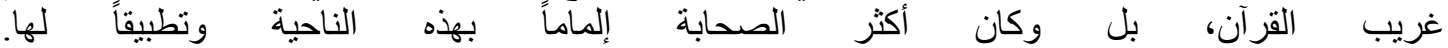

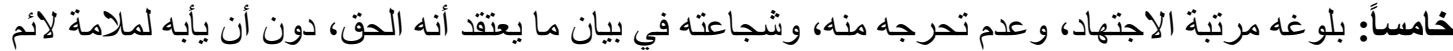

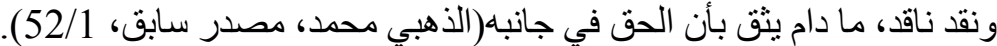

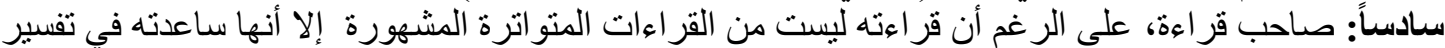

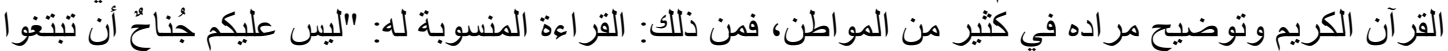

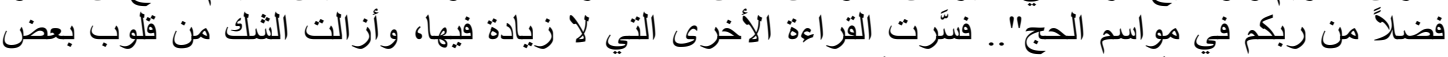

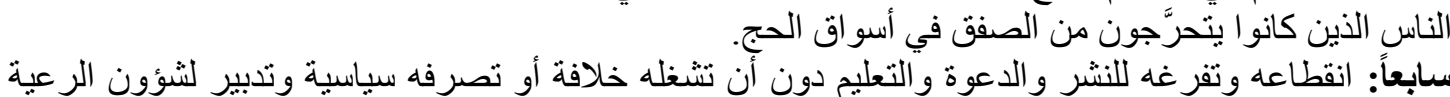

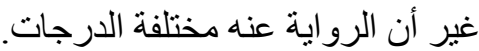

$$
\text { أما ابن مسعود م فترجع أسباب نبو غه وشهرته إلى أسباب منها: }
$$
أولاً: ملازمته للنبي صلى الله عليه وسلم وتقم إسلامه، فقد نقل عنه قوله: أخذت من فَيِّ رسول اله صلى الله عليه وسلم سبعين سورة. وقال عقبة بن عمرو: ما أدرى أحداً أعلم منه بما نزل على محمد ابن عبد عبد الله، فقال أبو موسى: إن تقل

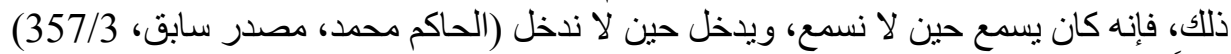
ثُانياً: انتسابه إلى قبيلة هذئة هذيل العربية الفصيحة.

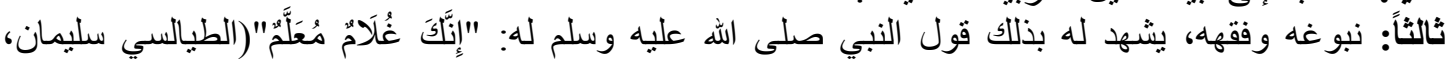

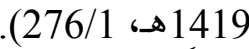

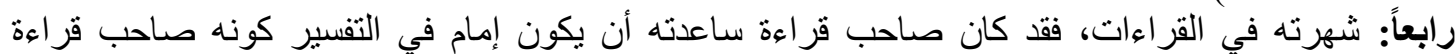

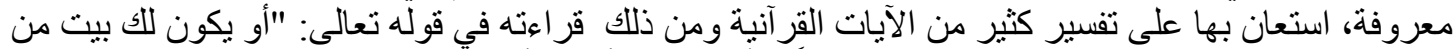

ذهب" تفسّر لفظ الزخرف في القر اءة المشهورة:

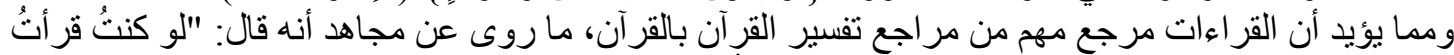

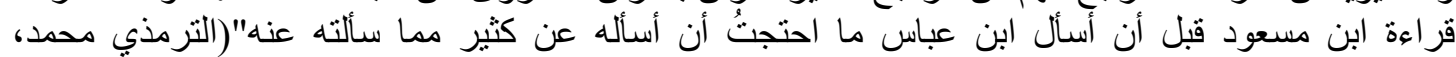

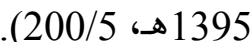
و هذا القول يدل على مدى أهمية قراءة ابن مسعود رضي الله عنده في تفسير القرآن الكريم.

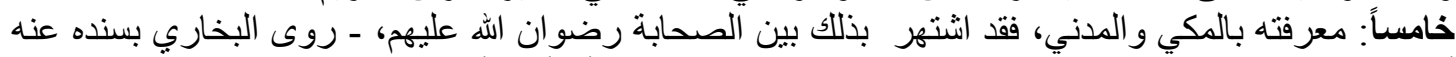

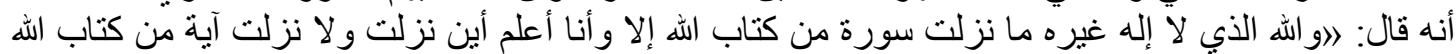

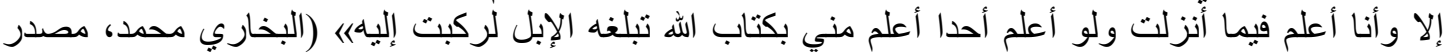
سابق، 187/6) وقد اعتبر كثير من العلماء ابن مسعود رضي الله عنه رائه رائد هذا العلم ومؤسسه. خصائص المدرستين

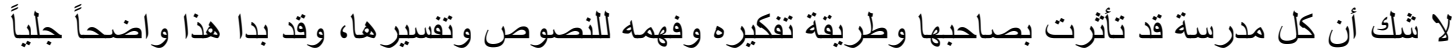

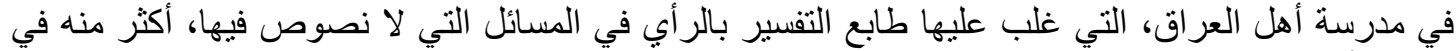

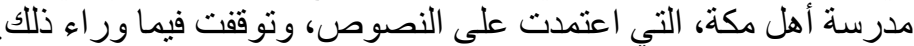

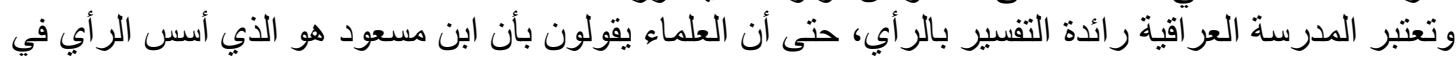

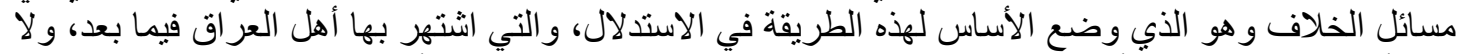

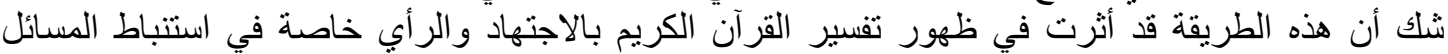

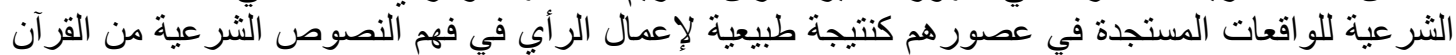
و السنة (عبد الجواد خلف، 1422هـ، 104). 


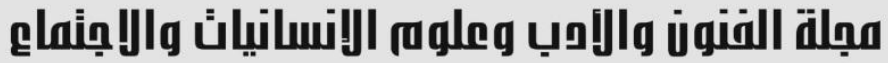

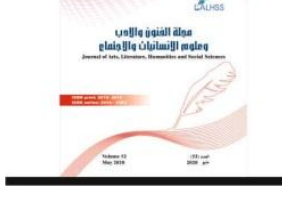

Journal of Arts, Literature, Humanities and Social Sciences

www.jalhss.com

Volume (52) May 2020

العدد (52) مايو 2020

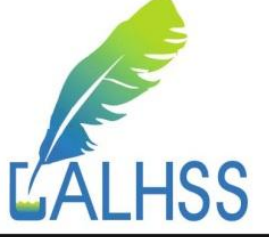

مكاتتهم في التفسير

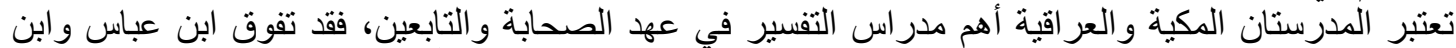

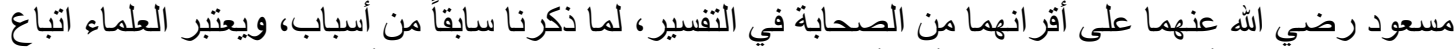

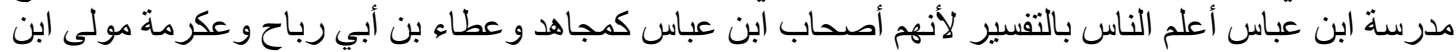

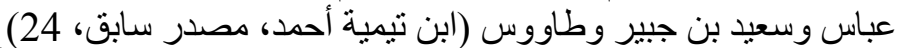

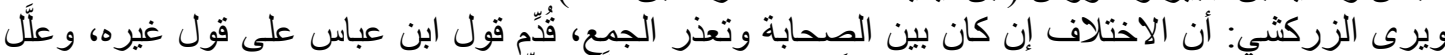

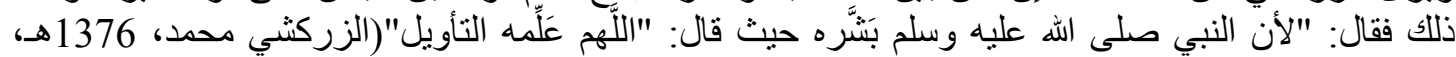

وذللك لمكانة ابن عباس رضي الهه عنهما بين الصحابة.

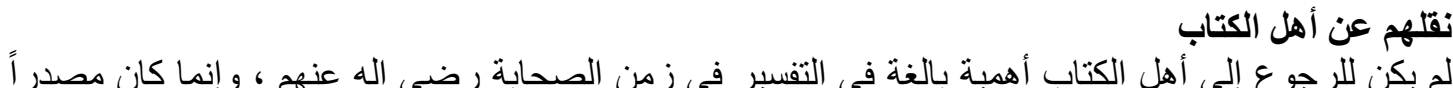

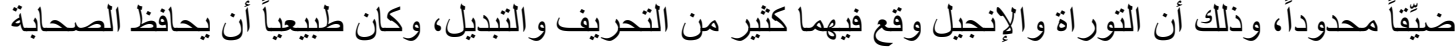

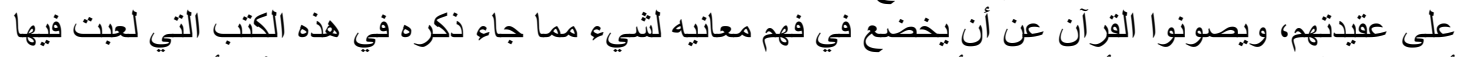

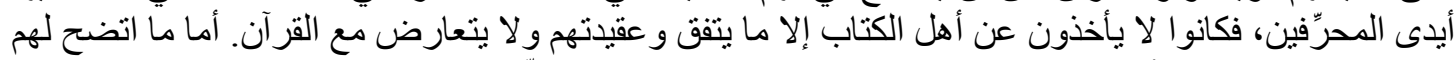

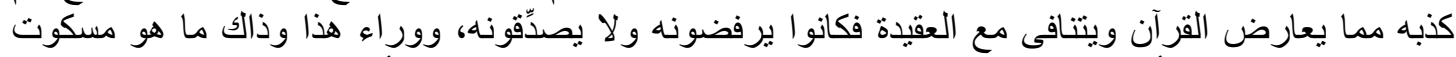

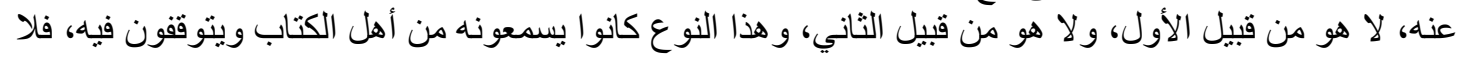

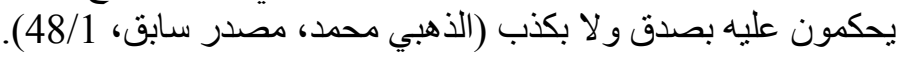

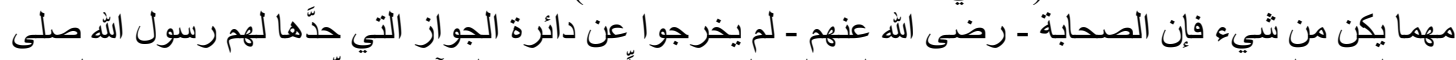

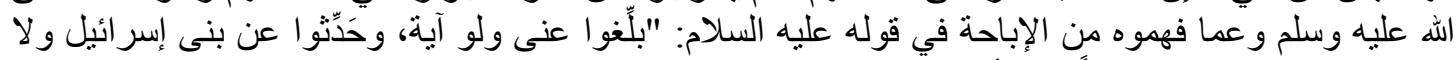

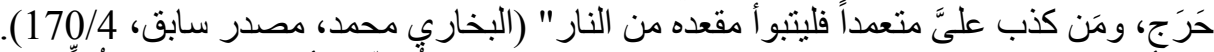

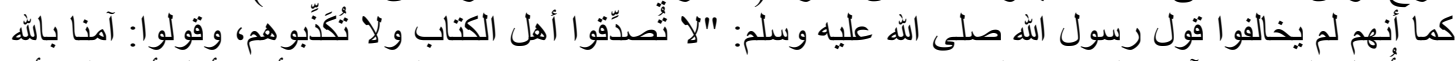

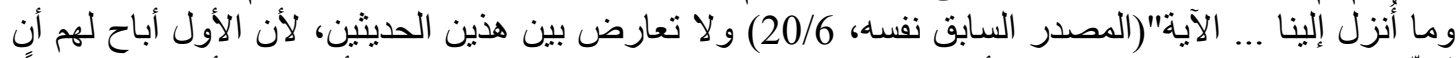

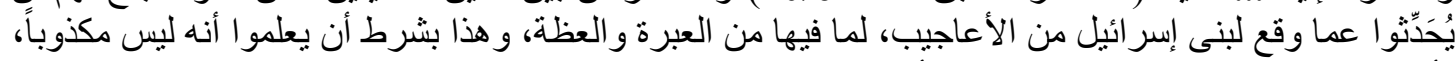

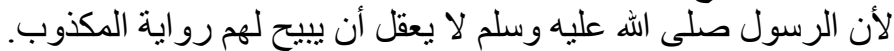

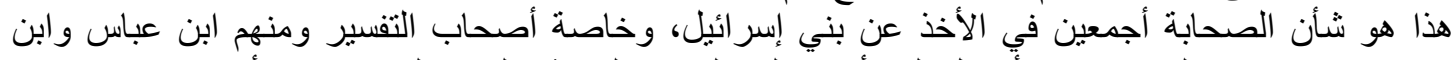

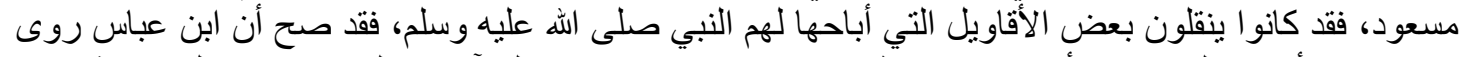

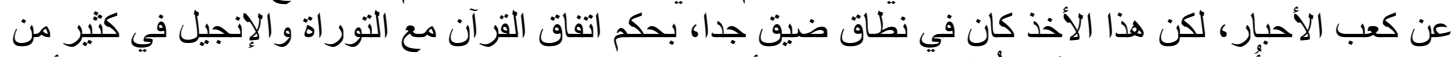

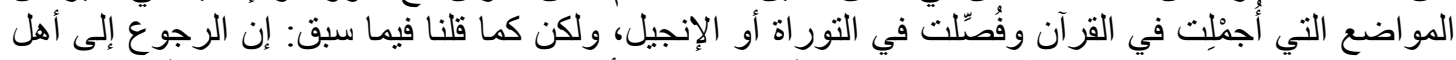

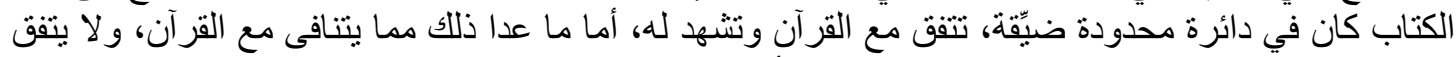

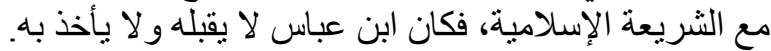

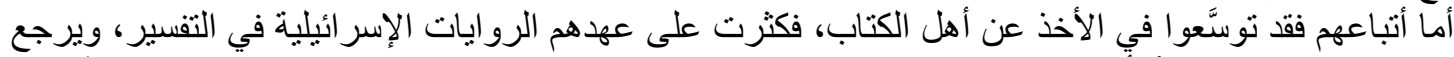

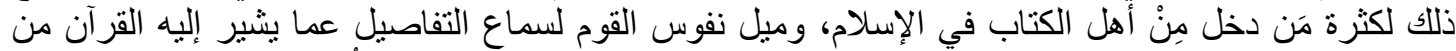

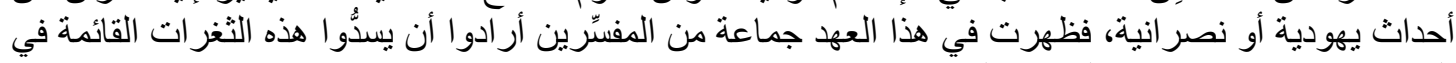

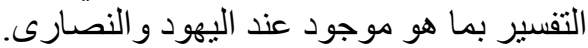

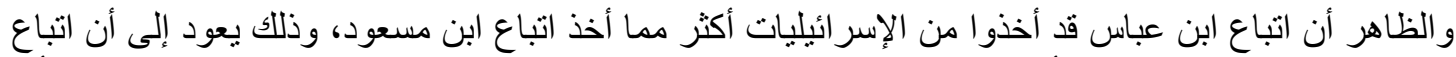

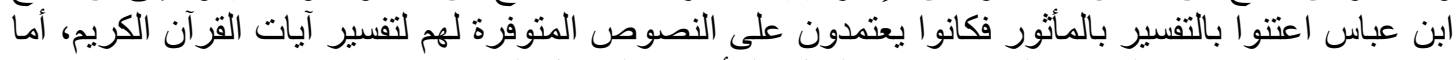

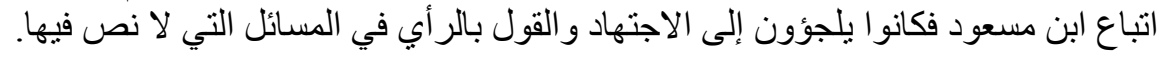




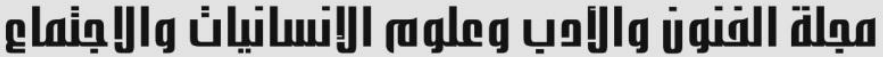

นust

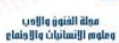

(1)

1. برز برز عدد كبير من الصحابة في تفسير القرآن الكريم، إلا أنهم تفاوتوا فيما يبنهم من حيث القلة والكثرة،

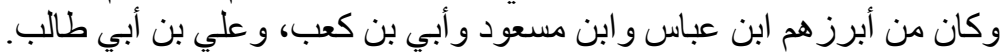

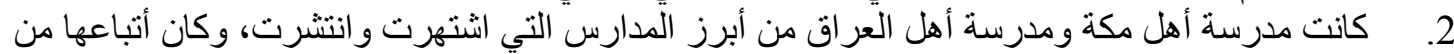
أعلام التابعين و علمائهم. 3. بأنور. أسس ابن عباس المدرسة المكية في التفسير ووضع نواتها في مكة، وقد اشتهرت بروايتها للتفسير

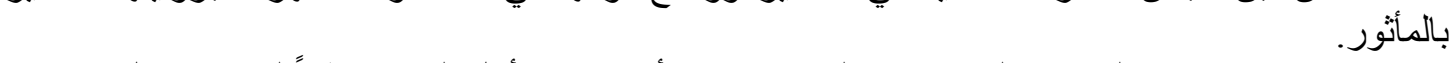
4. السس ابن مسعود المدرسة العر اقية في التفسير، وكان أتباعها من أهل العر اق نظراً لبعثه من قبل عمر بن الخطاب معلماً ووزير أن هناك. الك. 5. يعتبر المدرسة العراقية رائدة علم التفسير بالرأي، ويعتبر كثير من العلماء ابن مسعود واضع نواة التفسير بالر أي الذي اثتهر به أهل العر اق لاحقاً. 6. تميزت كل مدرسة من المدرستين بخصائص صاحبها ومؤسسها في التفسبر وكان لكل مدرسة طابعها

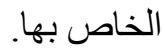
7. لم يتوسع ابن مسعود و ابن عباس في الأخذ من أهل الكتاب، إلا أن اتباعهم فيما بعد قد أخذوا من أهل

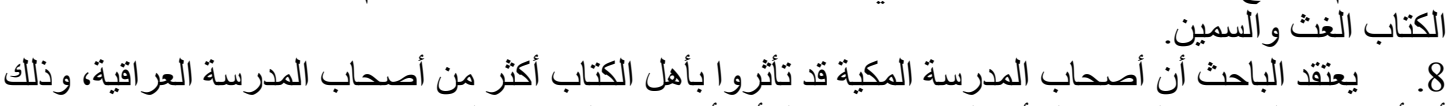

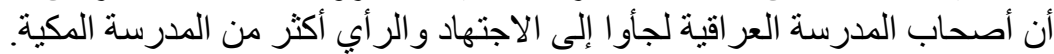
9. كان لهذين الددرستين فضل كبير بل الفضل الأكبر في تفسير القرآن الكريم ونشر علوم بين الكسلمين، ثم التأسيس لعصر التدوين في التفسير. 


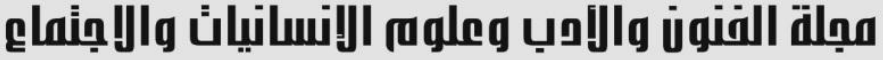

Journal of Arts, Literature, Humanities and Social Sciences www.jalhss.com

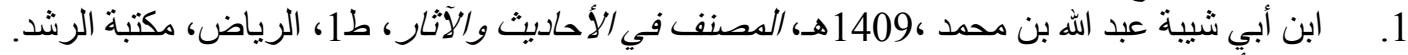

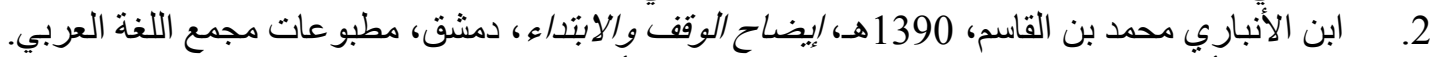

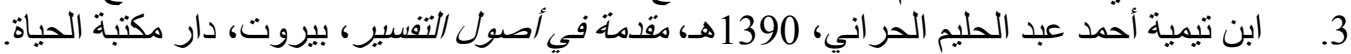

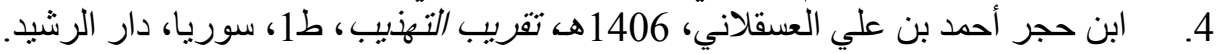

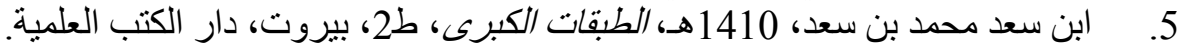

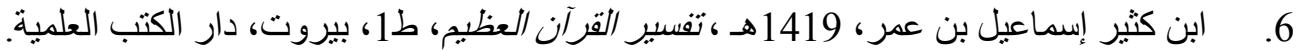
7.

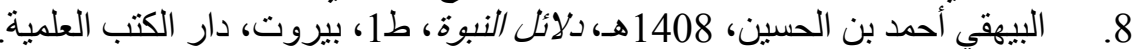

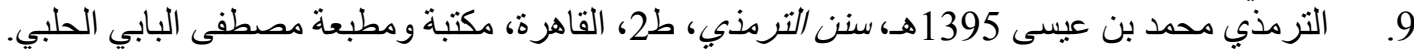

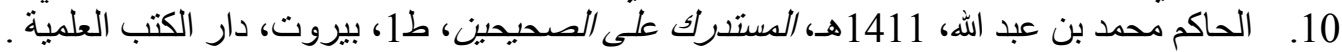

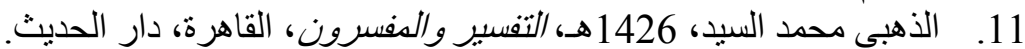

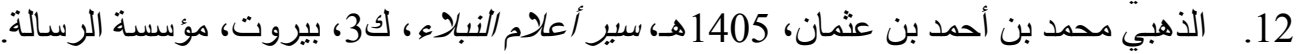
13.

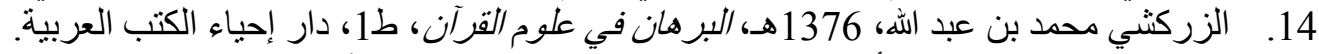

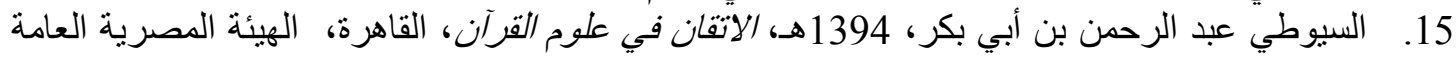

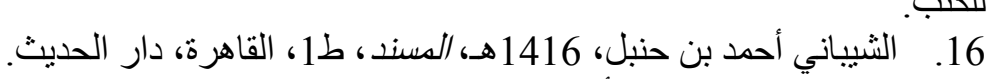
17. الطبراني سليمان بن أحمد، الدعجم الكبير، مكتبة ابن تيمية، القاهرة، ط2، تحقيق: حمدي عبد المجيد 18. " الطبري محمد بن جرير،1422 هـ، تفسير الطبري، ط1، الطب، مصر ، دار هجر للطباعة والنشر و التوزيع. 19.

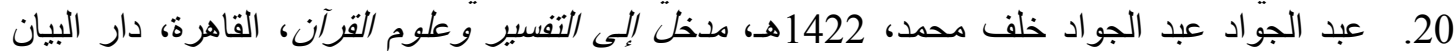

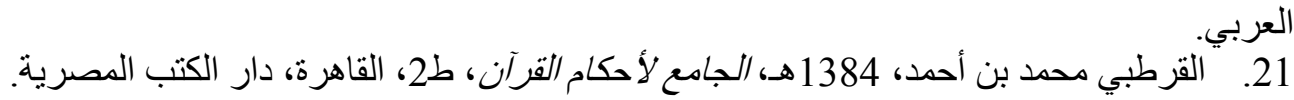

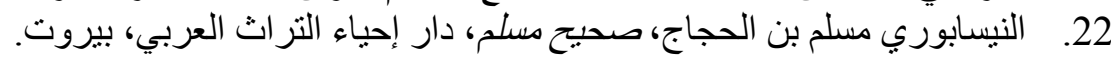




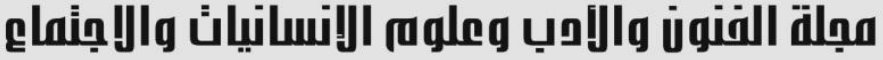 \\ Journal of Arts, Literature, Humanities and Social Sciences www.jalhss.com \\ Volume (52) May 2020 \\ العدد (52) مايو 2020}

\section{References}

1. Ibn Abi Shaybah, Abdullaah bin Muhammad Ibn Ibraaheem, Al-Musannaf, Arrushd library, Riyadh, 1st ed. $1409 \mathrm{H}$.

2. Ibn Al-Anbari, Muhammad Ibn Al-Qasim Ibn Muhammad, Idah al-waqf wa-l-ibtida fi kitab Allah, Majma' Al-lugha Al-Arabiya, Damascus, 1390 H.

3. Ibn Taymiyyah: Ahmad Abd Al-Halim Al-Harrani, Muqaddima fi usul al-tafsir, Dar Maktabat Al-Hayah, Beirut, $1390 \mathrm{H}$.

4. Ibn Hajar al-Asqalani, Ahmad ibn Ali al-Kannani al-Asqalani, Taqrib al-Tahdhib, Dar al-Rashid, Syria, 1st ed, $1406 \mathrm{H}$.

5. Ibn Saad, Muhammad Ibn Saad, Al-Tabaqat Al-Kubra, Dar Al-Kutub Al-Ilmiyah, Beirut, 1st ed., $1411 \mathrm{H}$.

6. Ibn Kathir, Ismail ibn Umar Ibn Kathir al-Qurashi Al-Damishqi, Tafsir al-Quran al-azim, Dar Al-Kutub Al-Ilmiyah, Beirut, 1st ed., $1419 \mathrm{H}$.

7. Al-Bukhary, Muhammad bin Ismail, al-Jami' al-Sahih al-Musnad min Hadith Rasul Allah wa Sunanih wa ayyamih known as Sahih Al-Bukhary, Dar Tawq al-Najah, 1st ed., $1422 \mathrm{H}$.

8. al-Bayhaqi, Ahmad bin al-Husayn al-Bayhaqi, Dala'il al-Nubuwwah, Dar Al-Kutub AlIlmiyah, Beirut, 1st ed., $1408 \mathrm{H}$.

9. Al-Tirmidhi , Muhammad ibn Isa ibn Surah, Sunan Al-tirmidhi, Maktabat wa matba'at Mustaf Al-Babi Al-Halabi, cairo, 2nd ed., 1395 H.

10. Al-Hakim, Muhammad ibn Abdullah al-Hakim al-Nishapuri, Al-Mustadrak 'ala AlSahihain, Dar Al-Kutub Al-Ilmiyah, Beirut, 1st ed., $1411 \mathrm{H}$.

11. al-Dhahabi, Muhammad Alsayed Muhammad, Al-Tafsir wa Al-mufassirun, Dar alhadith, Cairo, $1426 \mathrm{H}$.

12. al-Dhahabi, Muhammad ibn Ahmed ibn Othman, Siyar A'lam Al-Nubala', Mu'assassat al-Risalah, 3rd ed., Beirut, $1405 \mathrm{H}$.

13. Al-Zarqani, Muhammad 'Abd Al-'Azim, Manahil Al-'Irfan fi 'Ulum Al-Quran, tab'at Isa Al-Babi Al-Halabi, 3rd ed.

14. Al-Zarkashi Muhammad ibn Abdullah, Al-Burhan fi ulum Al-Qur'an, Dar Ihya' al Kutub al 'Arabiyah, 1st ed. Cairo, $1376 \mathrm{H}$.

15. Al-Suyuti, `Abd al-Rahman Ibn abi bakir, Al itqan fi ulum al quran, General Egyptian Book Organization, $1394 \mathrm{H}$.

16. Al-Shaybani, Ahmad bin Hanbal, al-Musnad, Tahqiq Ahmad Muhammad Shakir, Dar Al-Hadith, 1st ed., Cairo, $1416 \mathrm{H}$.

17. Al-Tabrani, Sulaiman Ibn Ahmed, Al-Mu'jam Al-Kabir, Tahqiq Hamdi Ibn Abdul Majeed Al Salafi, Maktabat Ibn Taymuyyah, 2nd ed. Cairo.

18. Al-Tabari, Muhammad ibn Jarir, Tafsir al-Tabari, Dar Hajar, 1st ed., Cairo, 1422 H.

19. Al-Tayalisi, Abu Dawood Sulaiman Ibn Dawod, Musnad Abi Dawud Al Tayalisi, Dar Hajar, 1st ed., Cairo, $1419 \mathrm{H}$.

20. Abduljawad, Abduljawad Khalaf Muhammad, Madkhal ila al-tafsir wa ulum alQuran, Dar Al-Bayan al-Arabi, Cairo.

21. Al-Qurtubi, Muhammmad Ibn Ahmed, Al-Jami' li Ahkam Al-Quran, Dar Al-Kutub Al-Misriyah, 2nd ed., Cairo, $1384 \mathrm{H}$.

22. Al-Naysaburi, Muslim ibn Al-Hajjaj, Sahih Muslim, Dar Ihya' al-Turath al-'Arabi, Beirut. 